\title{
Detection of a neonatal human rotavirus strain with VP4 and NSP4 genes of porcine origin
}

Correspondence
Joana D'Arc P. Mascarenhas
joanamascarenhas@iec.pa.gov.br

Received 17 March 2006

Accepted 14 November 2006
Joana D'Arc P. Mascarenhas, ${ }^{1}$ José Paulo G. Leite, ${ }^{2}$ Jackson C. Lima, ${ }^{1}$ Marcos B. Heinemann, ${ }^{2}$ Darleise S. Oliveira, ${ }^{1}$ Irene T. Araújo, ${ }^{2}$ Luana S. Soares, ${ }^{1}$ Rosa Helena P. Gusmão, ${ }^{3}$ Yvone B. Gabbay ${ }^{1}$ and Alexandre C. Linhares ${ }^{1}$

${ }^{1}$ Seção de Virologia, Instituto Evandro Chagas, Secretaria de Vigilância em Saúde, Ministério da Saúde, Belém, Brazil

${ }^{2}$ Departamento de Virologia, Instituto Oswaldo Cruz, Fundação Oswaldo Cruz, Rio de Janeiro, Brazil

${ }^{3}$ Universidade do Estado do Pará, Belém, Brazil

A human rotavirus strain (NB-150) was detected in stool samples from a neonate hospitalized for mild/moderate community-acquired diarrhoea. This baby lived in the outskirts of Belém, Brazil, under poor sanitation conditions. The NB-150 strain displayed a typical long electrophoretic pattern with 11 gene segments. It had two VP7 alleles, G1 and G4, and belonged to VP6 subgroup II. A close relatedness with human rotaviruses was shown for VP7 alleles: G1 (96.9-100\% similarity at the amino acid level) and G4 (97.1-100\% similarity at the amino acid level). As for VP6, 95.1-97.5\% similarity at the amino acid level was noted. VP8* and NSP4 genes showed a close relatedness with those of porcine rotavirus strains, as follows: VP8* ( $95.0 \%$ similarity at the amino acid level) and NSP4 (93.7-96.0\% similarity at the amino acid level). This is believed to be the first report in Brazil of a rotavirus infection involving a strain with G1 and G4 alleles, with VP8* and NSP4 genes of porcine origin. These findings strongly suggest the occurrence of interspecies transmission.

\section{INTRODUCTION}

Rotaviruses are worldwide enteric pathogens of a number of animal species including humans, cattle and pigs. In humans, rotavirus diarrhoea results in significant morbidity and mortality, especially in developing countries (Kapikian et al., 2001; Parashar et al., 2006). The rotavirus genome consists of 11 segments of double-stranded RNA (dsRNA), which encode 12 viral proteins: 6 structural proteins and 6 non-structural proteins (Estes, 2001). The segmented nature of the rotavirus genome provides a unique mechanism for the generation of genetic diversity through genetic reassortment that is likely to occur during in vivo and in vitro mixed infections (Ramig, 1997).

The intermediate capsid protein VP6 bears subgroup (SG) specificities that allow classification of group A rotaviruses

Abbreviations: EIA, enzyme immunoassay; e-type, RNA electropherotype; SG, subgroup.

The GenBank/EMBL/DDBJ accession numbers for the partial sequences of the neonatal rotavirus isolates are DQ299878 (VP6), DQ299877 (VP4), DQ299879 (VP7 G1), DQ299880 (VP7 G4) and DQ299876 (NSP4). into SGI, SGII, both SGI and II, or neither SG, as based on the reactivity with SG-specific monoclonal antibodies (Estes, 2001). A long RNA electropherotype (e-type) and SGI combination is typical of animal rotaviruses, while long e-type in conjunction with SGII (G1, G4, P[8], P[6]) and short e-type plus SGI G2P[4] strains are commonly found in human rotaviruses (Kapikian et al., 2001). Rotaviruses are in general typed by their two outer capsid proteins, VP4 (Ptype) and VP7 (G-type), and certain types predominate in natural infections of specific animal species (Gentsch et al., 1996, 2005).

The rotavirus non-structural protein NSP4 is encoded by gene segment 10 , and represents an intracellular receptor that mediates the acquisition of a transient membrane envelope as subviral particles bud into the endoplasmic reticulum. This protein has been studied extensively due to its role in viral morphogenesis and its potential enterotoxigenic property (Tian et al., 1995; Ball et al., 1996; Estes, 2001). NSP4 proteins from group A rotaviruses have been genetically classified into at least five (A-E) genotypes: A (KUN prototype), B (Wa), C (AU-1), D (WE) and E (avianlike) (Horie et al., 1997; Kirkwood \& Palombo, 1997; Ciarlet et al., 2000). In this report we describe the characterization 
of a neonatal rotavirus strain as based on the analysis of the $\mathrm{VP}^{\star}$ trypsin-cleavage fragment of the VP4, VP6, VP7 and NSP4 genes.

\section{METHODS}

Specimens. The neonatal strain NB-150 was collected during a hospital-based survey for rotavirus infection conducted from May 1996 to May 1998 in Belém, northern Brazil. This strain was obtained in the context of molecular epidemiological studies involving rotavirus strains infecting hospitalized neonates with community-acquired diarrhoea, nosocomial diarrhoea and asymptomatic nosocomial infection (Linhares et al., 2002). Of the 51 neonates excreting rotavirus, $50(98 \%)$ were $\mathrm{P}[6] \mathrm{G} 2$ and displayed a short etype profile. Of these, 26 were partially sequenced for VP4, VP7 and NSP4 genes; all strains were characterized as genotype G2 and NSP4 genotype A (Mascarenhas et al., 2006). The only exception was strain NB-150, recovered from a neonate with community-acquired diarrhoea, which showed long e-type, and G1 and G4 type specificities.

G-serotyping and subgrouping. G-serotyping and subgrouping were performed by enzyme immunoassay (EIA) using monoclonal antibodies specific for G1, G2, G3 and G4 types, and SGI and II, as described by Taniguchi et al. (1987) and Greenberg et al. (1983), respectively.

RNA extraction and typing by PCR. Viral dsRNA was extracted from faecal samples using silica powder glass (Boom et al., 1990), with modifications as described by Araújo et al. (2001). PAGE analysis was carried out in Tris-glycine buffer as previously described by Pereira et al. (1983). Multiplex PCR for G and P typing was made using a pool that consisted of G1-, G2-, G3-, G4- and G9- (Das et al., 1994), and $\mathrm{P}[8]-, \mathrm{P}[4]-, \mathrm{P}[6]-$ and $\mathrm{P}[9]$-specific primers (Gentsch et al., 1992). For amplification of VP6 and NSP4 genes, RT-PCR was carried out using VP6-F/VP6-R (Iturriza-Gómara et al., 2002) and Jrg30/Jrg31 (Cunliffe et al., 1997) to amplify 379 and 738 bp, respectively. All PCR products (VP8*, VP6, VP7 and NSP4) were purified by using a QIAquick PCR purification kit (Qiagen).

Cloning, sequencing and phylogenetic analysis. The partial length of the cDNA fragments of the 876 (VP8*), 904 (VP7) and 738 bp (NSP4) were cloned using a plasmidial-bacterial system. Purified amplicons were first ligated into a cloning pGEM-T Easy vector (Invitrogen) at the lac $Z \alpha$-peptide gene in order to obtain recombinant DNA. Plasmids with the inserted viral cDNA were then transformed and amplified in Escherichia coli competent bacteria (JM109 lineage) and the plasmids were recovered using the S.N.A.P. plasmid miniprep kit (Invitrogen). The nucleotide sequences of the cloned cDNA were determined by the dideoxy chain-termination method using the sequencing ABI PRISM dye terminator kit (Applied Biosystems) and resolved in an ABI 377 DNA sequencer. Universal primers designed on the basis of plasmid promoter region T7 and SP6 were used to sequence the recombinant DNA in both directions. Portions of the specific regions obtained from sequencing were as follows: VP8* gene (nt 11-887), VP7 gene (nt 37-941) and NSP4 gene (nt 1-738). The VP6 amplicon (379 bp, corresponding to nt 724-1103 of the coding region) was directly sequenced with the same primers used in PCR. The sequence alignment and phylogenetic analysis were done using the BioEdit editor (version 7.0) and MEGA package (version 3.1) using the neighbour-joining algorithm based on the Kimura two-parameters (Kimura, 1980) distance estimative method for nucleotide, providing statistical support with bootstrapping over 2000 replicates. For analysis, prototype strains for VP4, VP6, VP7 and NSP4 genes were obtained from GenBank at the National Center for Biotechnology Information, USA (http:// www.ncbi.nlm.nih.gov).

\section{RESULTS}

\section{Characterization of e-type, serotype/genotype and SG}

The NB-150 strain displayed a long e-type clearly showing 11 gene segments. NB-150 was found to have G1 and G4 specificities by EIA and PCR typing. This strain has shown to be SGII by EIA and PCR. NB-150 also demonstrated P[6] VP4 genotype and NSP4 genotype B of porcine origins.

\section{Analysis of cDNA cloning and sequencing}

The sequences from two clones of the VP8 ${ }^{*}$ gene and of two clones of the NSP4 gene were determined and assembled. The sequences of seven clones from the VP7 gene were also obtained revealing mixed G1 and G4 genotypes.

\section{VP6 analysis}

Sequence analysis of the VP6 gene confirmed results from both EIA and PCR genotyping assigning NB-150 strain to genogroup II, and therefore belonging to SGII (data not shown). The NB-150 strain denoted a close relatedness to two SGII human rotaviruses, $\mathrm{Wa}$ and RV3, showing 95.1-97.5\% amino acid identity, suggesting that neonatal NB-150 strain has a higher relatedness to SGII human strains than to porcine SGII (Table 1, Fig. 1). Specific amino acids at positions $305(\mathrm{~N}), 310(\mathrm{Q}), 315(\mathrm{Q}), 339(\mathrm{~N})$ and 342 (L) all predictive of human SGII specificity were conserved (data not shown).

\section{VP8* analysis}

The analysis of the deduced amino acid sequence of the VP8* subunit of VP4 (282 aa), corresponding to aa 1-282 of the coding region of the gene, was constructed including representative lineages following what has been outlined by Martella et al. (2006) with human and porcine strains. The NB-150 strain fell into lineage I, but did not cluster specifically with any of the sublineages (Ia, Ib, Ic and Id) proposed by these authors. In fact, NB-150 strain has shown a highest similarity to porcine sublineage $\mathrm{Ib}(95.0 \%)$. In contrast, the sequence of P[6]G2 of the NB-244 strain, which co-circulates along with the P[6]G1/G4 of the NB-150 strain, fell into human sublineage Ia as described by Martella et al. (2006) (Table 1, Fig. 2).

\section{VP7 analysis}

The nucleotide sequences of the NB-150 strain showed two alleles for the VP7 gene, G1 and G4. The analysis of the G1 allele was done using a sequence of 261 aa of 22 G1 human strains isolated from several countries, including representative lineages I to IV, as reported by Jin et al. (1996). Two porcine strains were also included in the analysis. The NB-150 strain fell in lineage I (bootstrap value of $79 \%$ ), showing a close relatedness to human rotavirus strains T73, B7402, Chi45 and 2TT, with $96.9-100 \%$ similarity. In contrast, strains Brz-5 and Brz-6, isolated from diarrhoeic children who 
Table 1. Percentage amino acid sequence similarities of VP6, VP8N, VP7 and NSP4 of neonatal rotavirus strain NB-150 as compared with several rotavirus strains

The highest identity is given in bold.

\begin{tabular}{|c|c|c|c|c|c|c|c|c|c|}
\hline \multirow{3}{*}{$\begin{array}{l}\text { Host } \\
\text { species }\end{array}$} & \multirow[t]{3}{*}{ Strain } & \multirow{3}{*}{$\begin{array}{l}\text { Subgroup } \\
\quad \text { (VP6) }\end{array}$} & \multirow{3}{*}{$\begin{array}{l}\text { Genotype } \\
\text { (VP4/VP7) }\end{array}$} & \multirow{3}{*}{$\begin{array}{c}\text { NSP4 } \\
\text { genotype }\end{array}$} & \multicolumn{5}{|c|}{ Percentage identity of NB-150 with: } \\
\hline & & & & & \multirow[t]{2}{*}{ VP6 } & \multirow[t]{2}{*}{ VP8 $^{*}$} & \multicolumn{2}{|c|}{ VP7 } & \multirow[t]{2}{*}{ NSP4 } \\
\hline & & & & & & & G1 & G4 & \\
\hline Human & RV3 & II & $\mathrm{P}[6], \mathrm{G} 3$ & B & 97.5 & 91.8 & & & 90.2 \\
\hline Human & $\mathrm{Wa}$ & II & $\mathrm{P}[8], \mathrm{G} 1$ & $\mathrm{~B}$ & 95.1 & & 94.2 & & 92.0 \\
\hline Human & US1205 & I & $\mathrm{P}[6], \mathrm{G} 9$ & A & 91.1 & 91.8 & & & \\
\hline Human & RMC321 & I & $\mathrm{P}[19], \mathrm{G} 9$ & $\mathrm{~B}$ & 89.5 & & & & 96.0 \\
\hline Porcine & A2 & $\mathrm{N}$ & $\mathrm{P}[7], \mathrm{G} 9$ & B & & & & & 93.7 \\
\hline Porcine & A253 & I & $\mathrm{P}[7], \mathrm{G} 11$ & $\mathrm{~B}$ & & & & & 95.4 \\
\hline Porcine & Gottfried & II & $\mathrm{P}[6], \mathrm{G} 4$ & B & 91.1 & 83.6 & & 93.0 & \\
\hline Porcine & OSU & I & $\mathrm{P}[7], \mathrm{G} 5$ & B & 88.7 & & & & 94.8 \\
\hline Human & CH61 & $\mathrm{N}$ & $\mathrm{P}[6], \mathrm{G} 1$ & B & & & & & 93.1 \\
\hline Simian & SA11 & I & $\mathrm{P}[2], \mathrm{G} 3$ & A & 92.7 & & & & \\
\hline Porcine & $221 / 04-13$ & I & $\mathrm{P}[6], \mathrm{G} 3$ & B & & 95.0 & & & \\
\hline Human & M37 & II & $\mathrm{P}[6], \mathrm{G} 1$ & B & & 92.1 & & & \\
\hline Human & NB244 & $\mathrm{N}$ & $\mathrm{P}[6], \mathrm{G} 2$ & A & & 88.8 & & & \\
\hline Human & ST3 & II & $\mathrm{P}[6], \mathrm{G} 4$ & B & & 90.0 & & 94.2 & 89.1 \\
\hline Porcine & $134 / 04-10$ & I & $\mathrm{P}[6], \mathrm{G} 3$ & B & & 89.3 & & & \\
\hline Porcine & $51-04$ & I & $\mathrm{P}[6], \mathrm{G} 4$ & B & & 85.9 & & & \\
\hline Human & $2 \mathrm{TT}$ & $\mathrm{N}$ & $\mathrm{N}, \mathrm{G} 1$ & $\mathrm{~N}$ & & & 100.0 & & \\
\hline Human & Chi-45 & $\mathrm{N}$ & $\mathrm{N}, \mathrm{G} 1$ & $\mathrm{~N}$ & & & 98.0 & & \\
\hline Human & B74-02 & $\mathrm{N}$ & $\mathrm{P}[8], \mathrm{G} 1$ & $\mathrm{~N}$ & & & 97.7 & & \\
\hline Human & T73 & $\mathrm{N}$ & $\mathrm{N}, \mathrm{G} 1$ & $\mathrm{~N}$ & & & 96.9 & & \\
\hline Human & Jp417 & $\mathrm{N}$ & $\mathrm{N}, \mathrm{G} 1$ & $\mathrm{~N}$ & & & 95.7 & & \\
\hline Human & Oh-40 & $\mathrm{N}$ & $\mathrm{N}, \mathrm{G} 1$ & $\mathrm{~N}$ & & & 95.0 & & \\
\hline Human & Isr-56 & $\mathrm{N}$ & $\mathrm{N}, \mathrm{G} 1$ & $\mathrm{~N}$ & & & 94.2 & & \\
\hline Human & Brz-5 & $\mathrm{N}$ & $\mathrm{N}, \mathrm{G} 1$ & $\mathrm{~N}$ & & & 93.1 & & \\
\hline Human & Brz-6 & $\mathrm{N}$ & $\mathrm{N}, \mathrm{G} 1$ & $\mathrm{~N}$ & & & 93.1 & & \\
\hline Porcine & C95 & I & $\mathrm{P}[7], \mathrm{G} 1$ & $\mathrm{~N}$ & & & 90.8 & & \\
\hline Human & R195 & $\mathrm{N}$ & $\mathrm{N}, \mathrm{G} 4$ & $\mathrm{~N}$ & & & & 100.0 & \\
\hline Human & Arg1662 & $\mathrm{N}$ & $\mathrm{P}[8], \mathrm{G} 4$ & $\mathrm{~N}$ & & & & 97.1 & \\
\hline Human & Arg958 & $\mathrm{N}$ & $\mathrm{P}[8], \mathrm{G} 4$ & $\mathrm{~N}$ & & & & 96.7 & \\
\hline Human & $\operatorname{Arg} 1620$ & $\mathrm{~N}$ & $\mathrm{P}[8], \mathrm{G} 4$ & $\mathrm{~N}$ & & & & 92.2 & \\
\hline Human & Odélia & $\mathrm{N}$ & $\mathrm{P}[8], \mathrm{G} 4$ & B & & & & 94.6 & \\
\hline Human & PV5249 & $\mathrm{N}$ & $\mathrm{P}[8], \mathrm{G} 4$ & $\mathrm{~N}$ & & & & 95.9 & \\
\hline Porcine & ArgP28 & $\mathrm{N}$ & $\mathrm{P}[6], \mathrm{G} 4$ & $\mathrm{~N}$ & & & & 80.0 & \\
\hline Human & KUN & I & $\mathrm{P}[4], \mathrm{G} 2$ & A & & & & & 83.4 \\
\hline Human & DS1 & I & $\mathrm{P}[4], \mathrm{G} 2$ & A & & & & & 83.4 \\
\hline Human & NB-140 & $\mathrm{N}$ & $\mathrm{P}[6], \mathrm{G} 2$ & A & & & & & 83.4 \\
\hline
\end{tabular}

N, Not available.

participated in a rotavirus vaccine trial in Belém, Brazil (Linhares et al., 1996), fell into lineage III (Table 1, Fig. 3). The divergence rates observed between NB-150 strain (lineage I) and prototype and strains from lineage III, Wa and Brz5 and Brz6 was of 5.8 and $6.9 \%$, respectively (data not shown).

A phylogenetic tree for allele G4 was constructed using a sequence of $735 \mathrm{nt}$, including the prototype ST3 strain and representative lineages assessed by Bok et al. (2002) and Arista et al. (2005). NB-150 strain fell into sublineage 1c (Fig. 4), closely related to G4 human rotavirus strains Arg1662 from Argentina (Bok et al., 2002), and R195 from Rio de Janeiro, Brazil (Volotão et al., 2006). The strains Arg1662 and R195 showed 97.1-100\% aa identity when comparing to NB-150 strain (Table 1). The divergence between NB-150 and ST3 was $5.8 \%$. 


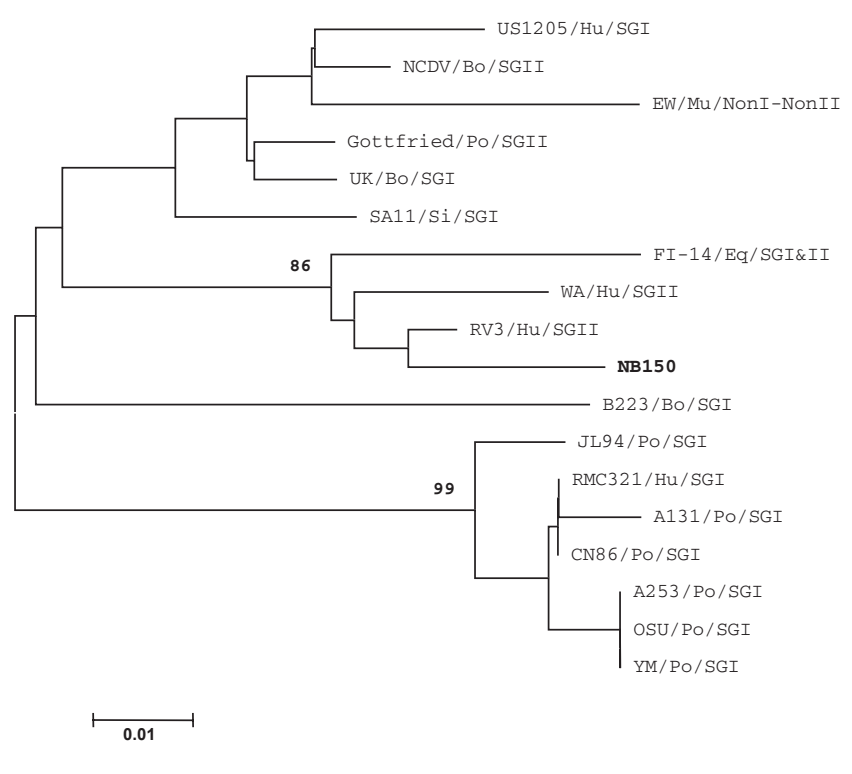

Fig. 1. Phylogenetic analysis of the NB-150 deduced amino acid sequence using the neighbour-joining method indicating its genetic relationship with VP6.

\section{NSP4 analysis}

A phylogenetic analysis of NSP4 protein was performed targeting 1 to $537 \mathrm{nt}$ of the coding region of gene 10, and included NSP4 genotypes A, B, C and D. NB-150 strain was found to be closely related to porcine rotaviruses, since it fell into NSP4 genotype B. The 175 aa long NSP4 protein was deduced and the NB-150 strain shared $93.7-95.4 \%$ amino acid similarity with genotype B porcine A2 strain, OSU strain and A253 strain and $96.0 \%$ amino acid similarity with an unusual human isolate, RMC321 (Table 1, Fig. 5).

The NB-150 strain showed potential N-linked glycosylation sites located at aa 8 and 18, two cysteine (C) residues conserved at aa 63 and 71 positions, a common aspartic acid (D) at position 19, proline $(\mathrm{P})$ residues at positions 28,34 , $52,138,165$ and 168 and a glutamine $(\mathrm{Q})$ residue at position 97 (Estes, 2001) (data not shown).

\section{DISCUSSION}

$\mathrm{P}[6]$ rotavirus strains are usually associated with asymptomatic infection (Steele et al., 1995; Pager et al., 2000; Cunliffe et al., 2002). P[6] genotype, associated with G1 and/ or G4 genotypes, has also been detected in children with diarrhoea (Araújo et al., 2002; Bányai et al., 2004; Leite et al., 1996; Mascarenhas et al., 2002; Ramachandran et al., 1996; Santos \& Hoshino, 2005; Steele \& Ivanoff, 2003; Timenetsky et al., 1994). A mixed G1 and G4 infection in a diarrhoeic child from Belém, Brazil, has been reported previously using monoclonal antibodies only (Mascarenhas et al., 1996). To our knowledge, neonatal NB-150 strain constitutes a unique finding in Brazil, since this strain has G1 and G4 alleles of human origin, and $\mathrm{VP}^{*}$ and NSP4 genes of porcine origin.

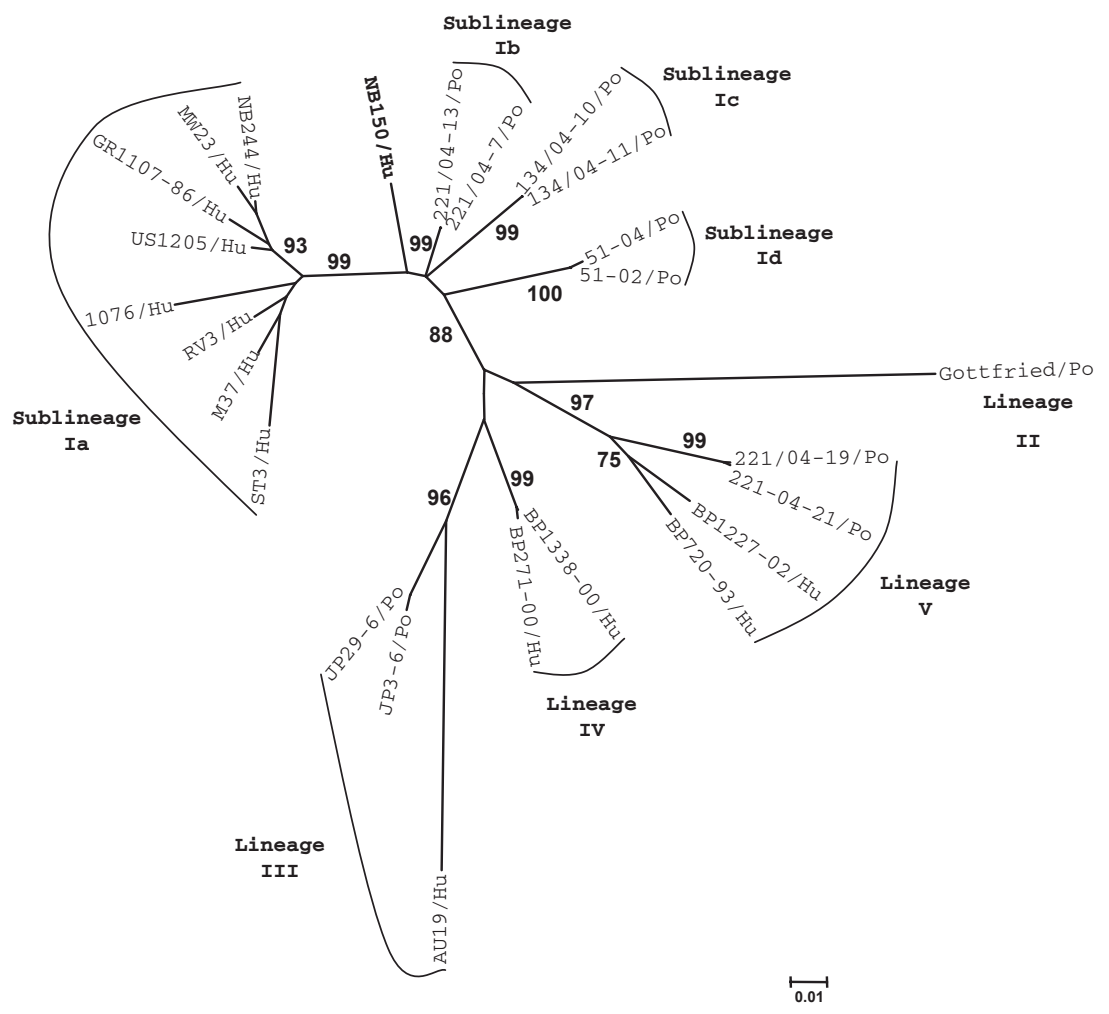

Fig. 2. Phylogenetic analysis of the NB-150 deduced amino acid sequence using the neighbour-joining method indicating its genetic relationship with VP8*. 


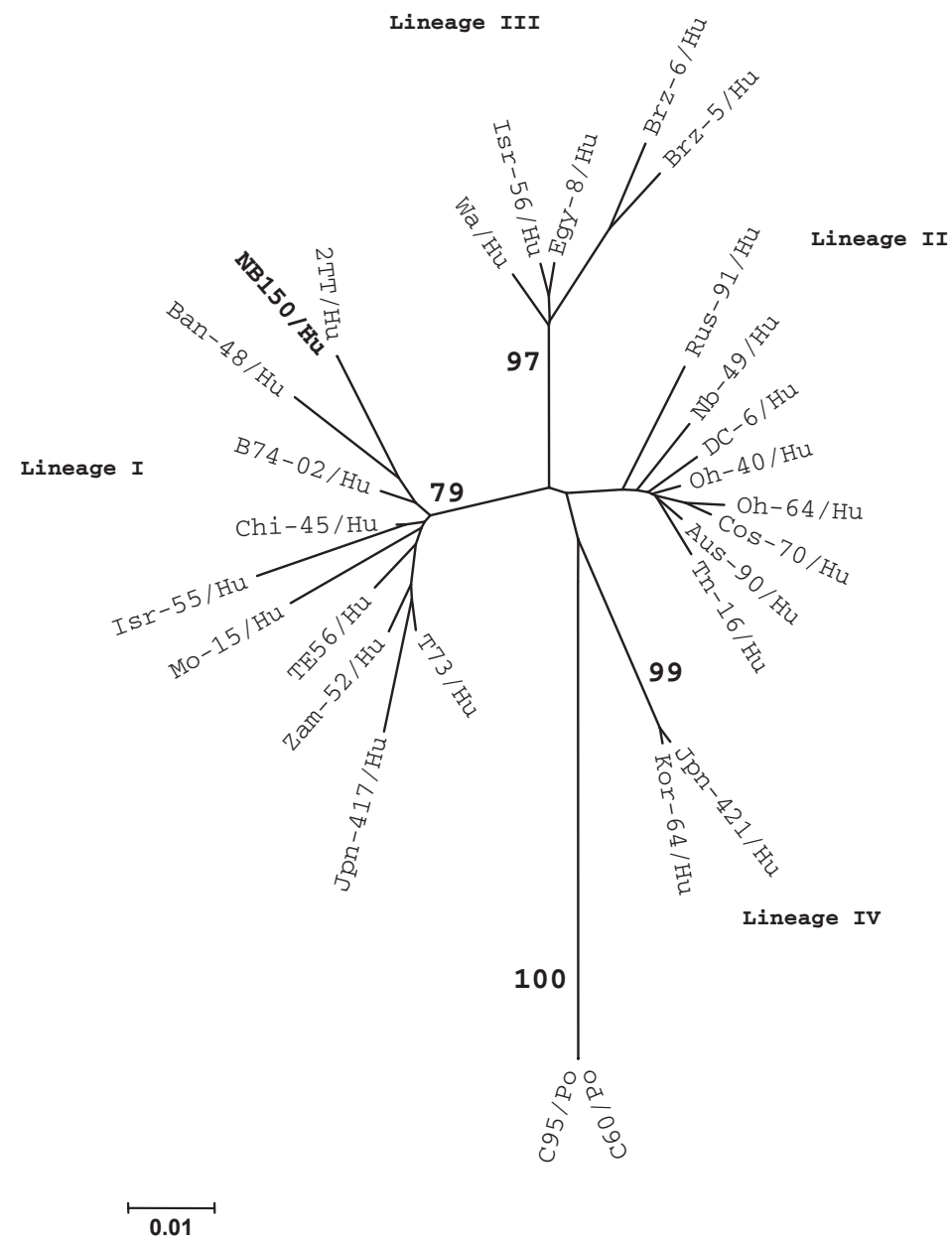

Fig. 3. Phylogenetic analysis of the NB-150 deduced amino acid sequence using the neighbour-joining method indicating its genetic relationship with VP7, allele G1.

On the other hand, studies conducted worldwide have demonstrated that G1 plus G4 rotavirus infection is uncommon. The frequencies of mixed infection by G1 and G4 serotypes are 3.2 and $16.1 \%$ in studies conducted in Australia and Cairo, respectively, on the basis of monoclonal antibodies (Bishop et al., 1991; Rawdan et al., 1997). In Ireland, O’Mahony et al. (1999) detected cases of rotavirus infection by G1/G4P[8] in $4 \%$ of the children based on reverse transcriptase PCR-based genotyping methods. Data on nucleic acid sequences were not available from these studies.

The close relationship between $\mathrm{P}[6]$ strains recovered from animals and humans has been characterized by Martella et al. (2006). These authors have detected porcine P[6] strains closely related to $\mathrm{P}[6]-\mathrm{I}$ and $\mathrm{P}[6]-\mathrm{V}$ human strains and distantly related to the porcine strain Gottfried, P[6]-II. The present study shows that the NB-150 strain clusters with $\mathrm{P}[6]-\mathrm{I}$ human and porcine strains but it is more related to porcine strains than to human strains. Accordingly, the $\mathrm{VP}^{\star}$ of strain NB-150 is likely of porcine origin, although being another sublineage. In contrast, NB-244 strain, recovered from a neonate with asymptomatic nosocomial infection associated with $\mathrm{P}[6] \mathrm{G} 2$ and that co-circulated along with the NB-150 strain and G1/G4P[6]-Ib strain, fell into human sublineage Ia as shown in Fig. 2. Such findings raise the hypothesis of an interspecies transmission involving humans and pigs. Evidence for genetic reassortment between human and animal rotaviruses has been reported particularly in cows and pigs (Martella et al., 2006; Santos \& Hoshino, 2005; Bányai et al., 2003; IturrizaGómara et al., 2003).

The G1 allele of NB-150 strain fell into lineage I and was most closely related to $2 \mathrm{TT}$ strain $(100 \%$ amino acid similarity). In contrast, it had $94.2 \%$ amino acid similarity when compared with prototype Wa or Brz-5 and Brz-6 strains; these two latter strains were recovered from children (placebo recipients) who participated in a rotavirus vaccine trial in Belém, Brazil, and were classified as belonging to lineage III (Jin et al., 1996). NB-150 strain, however, showed divergence of 5.8 and $6.9 \%$, respectively, when compared to prototype $\mathrm{Wa}$ and Brz5, and to Brz6 strains from lineage III.

G4 rotavirus serotype had previously been divided into two subtypes, namely subtype A (ST3-like) and subtype B (VA 70-like) (Gerna et al., 1988; Green et al., 1992). The sublineage Ic G4 viruses were first detected in Argentina in 1998 by Bok et al. (2002), followed by Uruguay in 1999 (Berois et al., 2003) and in Rio de Janeiro, Brazil, in 2000 


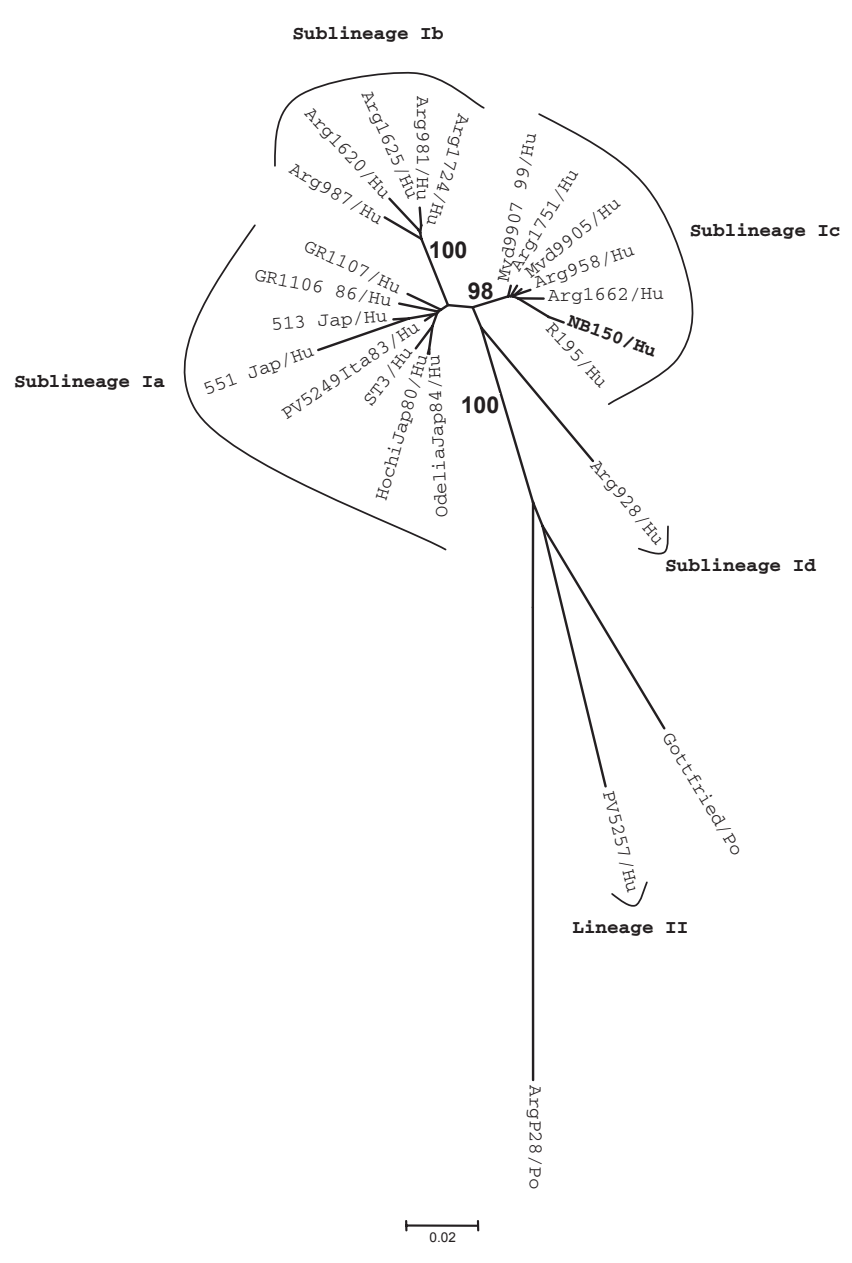

Fig. 4. Phylogenetic analysis of the NB-150 deduced nucleotide sequence using the neighbour-joining method indicating its genetic relationship with VP7, allele G4.

(Volotão et al., 2006). The NB-150 strain currently has data going back to 1997 (Linhares et al., 2002) and falls into lineage 1c. Of note, the divergence observed between the NB-150 strain and the ST3 prototype was $5.4 \%$.

In considering that a mixed G1 and G4 infection has occurred, it seems likely that e-types of both viruses have fully overlapped, as 11 segments only could be identified. Although G1 and G4 serotype specificities may raise the hypothesis of a single rotavirus strain bearing a dual VP7 specificity, such an event seems very unlikely, as based on previous studies in Brazil (Genstch et al., 2005; Santos \& Hoshino, 2005) and other countries, where mixed rotavirus infections are common events (Fischer et al., 2005; Rahman et al., 2005).

The potential role of NSP4 in virulence and in the understanding of diversity within NSP4 genotypes among species may be of importance, as NSP4 seems to play a role in immunity and possibly in protection (Ball et al., 2005). Sequence analyses indicate that NSP4 genotype A does not

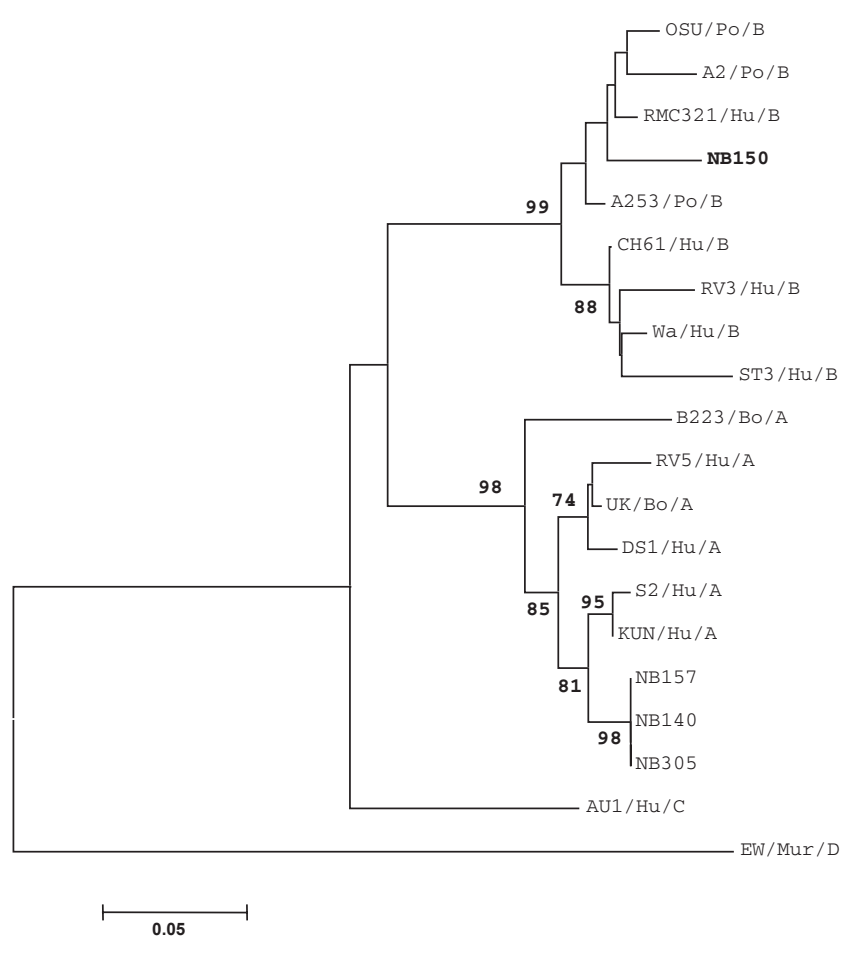

Fig. 5. Phylogenetic analysis of the NB-150 deduced amino acid sequence using the neighbour-joining method indicating its genetic relationship with NSP4.

correlate with SG specificity. However, a correlation between SG specificity and NSP4 type in NSP4 genotypes B, C and D may exist (Ciarlet et al., 2000). During an epidemic of infantile gastroenteritis in Manipur, India, a rotavirus RMC321 strain was obtained from a child, showing long e-type, SGI, G9P[19] and NSP4 genotype B (Varghese et al., 2004). In turn, neonatal NB-150 strain had long e-type and was SGII, G1 + G4P[6] and NSP4 genotype B. Sequence analysis of NSP4, however, strongly suggests a porcine origin for both strains. Strain RMC321 is likely to be of animal origin in all its genome segments, has long e-type, SGI and NSP4 B, whereas NB-150 appears to be a primarily human strain but having porcine-like NSP4 and $\mathrm{VP} 8^{\star}$ genes probably due to reassortment.

The findings from NSP4 genetic analyses lead us to postulate an interspecies transmission for NB-150 neonatal strain. Transmission of animal rotaviruses to humans is expected to occur more frequently in developing countries, where people live in close proximity to animals (mostly bovine, porcine and chickens), and in general under poor sanitary conditions (Jain et al., 2001). It is worth noting that in this context, however, a rotavirus strain has been isolated recently from a child with gastroenteritis in Belgium, with a genomic analysis demonstrating a significant relatedness to lapine rotaviruses, which highly suggests either a full lapine origin or a result of natural reassortment for this unusual strain (Matthijnssens et al., 2006). In Brazil, several reports 
have shown strains of porcine origin, mostly G5 and G9 serotypes, causing diarrhoea in children, and suggesting a frequent exchange of genetic material among co-circulating human and animal rotavirus strains (Alfieri et al., 1996; Leite et al., 1996; Timenetsky et al., 1997; Gouvea \& Santos, 1999; Mascarenhas et al., 2002; Santos et al., 2005). It seems likely that NB-150 strain was a result of transmission from pigs to humans, since there are only a few genes of porcine origin in human-derived rotavirus strain and not vice versa. Of note in this context, it has been reported that pigs are in general more susceptible to human rotaviruses than any other species, suggesting that the products of at least some of the genes should be determinants of the host range restriction inherent to mammalian group A rotaviruses (Rao et al., 1995; Santos et al., 1999). Genetic and phylogenetic analyses of structural and non-structural genes have indicated a consistent pattern of evolutionary relationships between certain animal and human viruses, as based on comparisons of VP6, NSP1, NSP3, NSP4 and NSP5 (Dunn et al., 1994; Cunliffe et al., 1997; Fujiwara \& Nakagomi, 1997; Horie et al., 1997; Kirkwood \& Palombo, 1997; Iturriza-Gómara et al., 2003). In this study, phylogenetic analyses of VP6 and VP7 genes have shown a close relatedness between the neonatal NB-150 rotavirus strain and human rotaviruses. In addition, sequence analyses of VP4 and NSP4 genes sustain a close relatedness with the porcine strains.

Evidence for genetic reassortment between human and animal rotaviruses has been reported in several studies (Das et al., 1993). The neonate from whom NB-150 was recovered lived in the outskirts of Belém, Brazil, under poor sanitation and in close contact with domestic animals, including pigs. A study limitation is that no faecal specimens were collected from pigs living in the same environment, so a more firm conclusion could not be drawn as to the interspecies transmission issue. An additional limitation of our study was that the NB-150 strain could not be cell cultured due to local technical constraints. Plaque purification procedures would clearly add further evidence in favour of the hypothesis of mixed infection. Simultaneous surveillance and sequencing of rotavirus genes from animals and humans are essential for a better understanding of the relationship between co-circulating strains with common and uncommon G/P combinations. Moreover, this would significantly contribute to a better assessment of the ample genetic diversity of rotaviruses.

Our study provides evidence to support the hypothesis that there is a dynamic interaction between rotaviruses of human and animal origins. Consequently, reassortment events can lead to a stable introduction and successful spread of animal gene alleles into human rotavirus genomes.

In summary, we have identified a human rotavirus strain that displays an unusual combination with long e-type pattern, G1 and G4 specificities, and belongs to SGII. VP7 and VP6 genes were closely related to rotavirus strains of human origin but phylogenetic analyses demonstrated that $\mathrm{VP}^{\star}{ }^{\star}$ and NSP4 genes were clustering with those of porcine strains. The findings from our study suggest that animal rotaviruses may cross the species barrier and even cause diarrhoea in humans. This can be regarded as a key step in acquiring a better understanding of rotavirus evolution and ecology. Moreover, interspecies transmission may possibly pose potential difficulties in future strategies toward the development of rotavirus vaccines.

\section{ACKNOWLEDGEMENTS}

We thank Dr Márcio Nunes and Dr Olinda Macêdo for their valuable advice in cloning and sequencing, and Mrs Euzeni Menezes for technical assistance. In addition, we would like to thank the IEC/SVS, COTEC/SECTAM/PA, IOC/FIOCRUZ and PIBIC/CNPq/Brazil for financial and administrative support.

\section{REFERENCES}

Alfieri, A. A., Leite, J. P., Nakagomi, O., Kaga, E., Woods, P. A., Glass, R. I. \& Gentsch, J. R. (1996). Characterization of human rotavirus genotype P[8]G5 from Brazil by probe-hybridization and sequence. Arch Virol 141, 2353-2364.

Araújo, I. T., Ferreira, M. S., Fialho, A. M., Assis, R. M., Cruz, C. M., Rocha, M. \& Leite, J. P. (2001). Rotavirus genotypes P[4]G9, P[6]G9, and P[8]G9 in hospitalized children with acute gastroenteritis in Rio de Janeiro, Brazil. J Clin Microbiol 39, 1999-2001.

Araújo, I. T., Fialho, A. M., de Assis, R. M., Rocha, M., Galvao, M., Cruz, C. M., Ferreira, M. S. \& Leite, J. P. (2002). Rotavirus strain diversity in Rio de Janeiro, Brazil: characterization of VP4 and VP7 genotypes in hospitalized children. J Trop Pediatr 48, 214-218.

Arista, S., Giammanco, G. M., De Grazia, S., Colomba, C. \& Martella, V. (2005). Genetic variability among serotype G4 Italian human rotaviruses. J Clin Microbiol 43, 1420-1425.

Ball, J. M., Tian, P., Zeng, C. Q., Morris, A. P. \& Estes, M. K. (1996). Age-dependent diarrhoea induced by a rotaviral nonstructural glycoprotein. Science 272, 101-104.

Ball, J. M., Mitchell, D. M., Gibbons, T. F. \& Parr, R. D. (2005). Rotavirus NSP4: a multifunctional viral enterotoxin. Viral Immunol 18, 27-40.

Bányai, K., Gentsch, J. R., Griffin, D. D., Holmes, J. L., Glass, R. I. \& Szucs, G. (2003). Genetic variability among serotype G6 human rotaviruses: identification of a novel lineage isolated in Hungary. J Med Virol 71, 124-134.

Bányai, K., Martella, V., Jakab, F., Melegh, B. M. \& Szücs, G. (2004). Sequencing and phylogenetic analysis of human genotype P[6] rotavirus strains detected in Hungary provides evidence for genetic heterogeneity within the P[6] VP4 gene. J Clin Microbiol 42, 43384343.

Berois, M., Libersou, S., Russi, J., Arbiza, J. \& Cohen, J. (2003). Genetic variation in the VP7 gene of human rotavirus isolated in Montevideo-Uruguay from 1996-1999. J Med Virol 71, 456-462.

Bishop, R. F., Unicomb, L. E. \& Barnes, G. L. (1991). Epidemiology of rotavirus serotypes in Melbourne, Australia, from 1973 to 1989. J Clin Microbiol 29, 862-868.

Bok, K., Matson, D. O. \& Gómez, J. A. (2002). Genetic variation of capsid protein VP7 in genotype G4 human rotavirus strains: simultaneous emergence and spread of different lineages in Argentina. J Clin Microbiol 40, 2016-2022.

Boom, R., Sol, C. J. A., Salimans, M. M. M., Jansen, C. L., WertheimVan Dillen, P. M. E. \& Van Der Noordaa, J. (1990). Rapid and simple 
method for purifications of nucleic acids. J Clin Microbiol 28 495-503.

Ciarlet, M., Liprandi, F., Conner, M. E. \& Estes, M. K. (2000). Species specificity and interspecies relatedness of NSP4 genetic groups by comparative NSP4 analysis of animal rotaviruses. Arch Virol 145, 371-383.

Cunliffe, N. A., Rogerson, S., Dove, W., Thindwa, B. D. M., Greensill, J., Kirkwood, C. D., Broadhead, R. L. \& Hart, C. A. (2002). Detection and characterization of rotaviruses in hospitalized neonates in Blantyre, Malawi. J Clin Microbiol 40, 1534-1537.

Cunliffe, N. A., Woods, P. A., Leite, J. P. G., Das, B. K., Ramachandran, M., Bhan, M. K., Hart, C. A., Glass, R. I. \& Gentsch, J. R. (1997). Sequence analysis of NSP4 gene of human rotavirus allows classification into two main genetic groups. $J \mathrm{Med}$ Virol 53, 41-50.

Das, B. K., Gentsch, J. R., Cicirello, H. G., Woods, P. A., Ramachandran, M., Gupta, A., Kumar, R., Bhan, M. K. \& Glass, R. I. (1994). Characterization of rotavirus strains from newborns in New Delhi, India. J Clin Microbiol 32, 1820-1822.

Das, B. K., Gentsch, J. R., Hoshino, Y., Ishida, S.-I., Nakagomi, O., Bhan, M. K., Kumar, R. \& Glass, R. I. (1993). Characterization of the G serotype and genogroup of New Delhi newborn rotavirus strain 116E. Virology 197, 99-107.

Dunn, S. J., Burns, J. W., Cross, T. L., Vo, P. T., Ward, R. L., Bremont, M. \& Greenberg, H. B. (1994). Comparison of VP4 and VP7 of five murine rotavirus strains. Virology 203, 250-259.

Estes, M. K. (2001). Rotaviruses and their replication. In Fields Virology, 4th edn, pp. 1747-1785. Edited by D. M. Knipe, P. M. Howley. Philadelphia, PA: Lippincott Williams \& Wilkins.

Fischer, T. K., Eugen-Olsen, J., Pedersen, A. G., Molbak, K., Bottiger, B., Rostgaard, K. \& Nielsen, N. M. (2005). Characterization of rotavirus strains in a Danish population: high frequency of mixed infections and diversity within the VP4 gene of P[8] strains. J Clin Microbiol 43, 1099-1104.

Fujiwara, Y. \& Nakagomi, O. (1997). Interspecies sharing of two distinct nonstructural protein 1 alleles among human and animal rotaviruses as revealed by dot blot hybridization. J Clin Microbiol 35, 2703-2705.

Gentsch, J. R., Glass, R. I., Woods, P., Gouvea, V., Gorziglia, M., Flores, J., Das, B. K. \& Bhan, M. K. (1992). Identification of group A rotavirus gene 4 types by polymerase chain reaction. J Clin Microbiol 30, 1365-1373.

Gentsch, J. R., Woods, P. A., Ramachandran, M., Das, B. K., Leite, J. P., Alfieri, A., Kumar, R., Bhan, M. K. \& Glass, R. I. (1996). Review of $G$ and $P$ typing results from a global collection of rotavirus strains: implications for vaccine development. J Infect Dis 174, 30-36.

Gentsch, J. R., Laird, A. R., Bielfelt, B., Griffin, D. D., Bányai, K., Ramachandran, M., Jain, V., Cunliffe, N. A., Nakagomi, O. \& other authors (2005). Serotype diversity and reassortment between human and animal rotavirus strains: implications for rotavirus vaccine programs. J Infect Dis 192, 146-159.

Gerna, G., Sarasini, A., di Matteo, A., Parea, M., Orsolini, P. \& Battaglia, M. (1988). Identification of two subtypes of serotype 4 human rotavirus by using VP7-specific neutralizing monoclonal antibodies. J Clin Microbiol 26, 1388-1392.

Gouvea, V. \& Santos, N. (1999). Rotavirus serotype G5: an emerging cause of epidemic childhood diarrhea. Vaccine 17, 1291-1292.

Green, K. Y., Sarasini, A., Qian, Y. \& Gerna, G. (1992). Genetic variation in rotavirus serotype 4 subtypes. Virology 188, 362-368.

Greenberg, H., McAuliffe, V., Valdesuso, J., Wyatt, R., Flores, J., Kalica, A., Hoshino, Y. \& Singh, N. (1983). Serological analysis of the subgroup protein of rotavirus, using monoclonal antibodies. Infect Immun 39, 91-99.

Horie, Y., Masamune, O. \& Nakagomi, O. (1997). Three major alleles of rotavirus NSP4 proteins identified by sequence analysis. J Gen Virol 78, 2341-2346.

Iturriza-Gómara, M., Wong, C., Blome, S., Desselberger, U. \& Gray, J. (2002). Molecular characterization of VP6 genes of human rotavirus isolates: correlation of genogroups with subgroups and evidence of independent segregation. J Virol 76, 6596-6601.

Iturriza-Gómara, M., Anderton, E., Kang, G., Gallimore, C., Phillips, W., Desselberger, U. \& Gray, J. (2003). Evidence for genetic linkage between the gene segments encoding NSP4 and VP6 proteins in common and reassortant human rotavirus strains. J Clin Microbiol 41, 3566-3573.

Jain, V., Das, B. K., Bhan, M. K., Glass, R. I., Gentsch, J. R. and the Indian Strain Surveillance Collaborating Laboratories. (2001). Great diversity of group A rotavirus strains and high prevalence of mixed rotavirus infections in India. J Clin Microbiol 39, 3524-3529.

Jin, Q., Ward, R. L., Knowlton, D. R., Gabbay, Y. B., Linhares, A. C., Rappaport, R., Woods, P. A., Glass, R. I. \& Gentsch, J. R. (1996). Divergence of VP7 genes of G1 rotaviruses isolated from infants vaccinated with reassortant rhesus rotaviruses. Arch Virol 141, 2057-2076.

Kapikian, A. Z., Hoshino, Y. \& Chanock, R. M. (2001). Rotaviruses. In Fields Virology, 4th edn, pp. 1787-1833. Edited by D. M. Knipe \& P. M. Howley. Philadelphia, PA: Lippincott Williams \& Wilkins.

Kimura, M. (1980). A simple method for estimating evolutionary rate of base substitution through comparative studies of nucleotide sequences. J Mol Evol 16, 111-120.

Kirkwood, C. D. \& Palombo, E. A. (1997). Genetic characterization of the rotavirus nonstructural protein, NSP4. Virology 236, 258-265.

Leite, J. P. G., Alfieri, A. A., Woods, P. A., Glass, R. I. \& Gentsch, J. R. (1996). Rotavirus $G$ and $P$ types circulating in Brazil: characterization by RT-PCR, probe hybridization, and sequence analysis. Arch Virol 141, 2365-2374.

Linhares, A. C., Gabbay, Y. B., Mascarenhas, J. D. P., De Freitas, R. B., Oliveira, C. S., Bellesi, N., Monteiro, T. A. F., Lins-Lainson, Z., Ramos, F. L. P. \& Valente, S. A. (1996). Immunogenicity, safety and efficacy of rhesus-human, reassortant rotavirus vaccine in Belém, Brazil. Bull World Health Organ 74, 491-500.

Linhares, A. C., Mascarenhas, J. D. P., Gusmão, R. H. P., Gabbay, Y. B., Fialho, A. M. \& Leite, J. P. G. (2002). Neonatal rotavirus infection in Belém, northern Brazil: nosocomial transmission of a P[6]G2 strain. J Med Virol 67, 418-426.

Martella, V., Banyai, K., Ciarlet, M., Iturriza-Gómara, M., Lorusso, E., De Grazia, S., Arista, S., Decaro, N., Elia, G. \& other authors (2006). Relationships among porcine and human $\mathrm{P}[6]$ rotaviruses: evidence that the different human $\mathrm{P}[6]$ lineages have originated from multiple interspecies transmission events. Virology 344, 509-519.

Mascarenhas, J. D., Gusmao, R. H., Gabbay, Y. B., Monteiro, T. A., Gomes, J. B. \& Linhares, A. C. (1996). Concomitant rotavirus serotypes 1 and 4 infections in a diarrhoeic child from Belem, Brazil. Rev Inst Med Trop Sao Paulo 38, 249-252.

Mascarenhas, J. D. P., Linhares, A. C., Gabbay, Y. B. \& Leite, J. P. G. (2002). Detection and characterization of rotavirus $G$ and $P$ types from children participating in a rotavirus vaccine trial in Belém, Brazil. Mem Inst Oswaldo Cruz 97, 113-117.

Mascarenhas, J. D. P., Linhares, A. C., Bayma, A. P. G., Lima, J. C., Sousa, M. S., Araújo, I. T., Heinemann, M. B., Gusmão, R. H. P., Gabbay, Y. B. \& Leite, J. P. G. (2006). Molecular analysis of VP4, VP7 and NSP4 genes of P[6]G2 rotavirus genotype strains recovered from hospitalised neonates in Belém, Brazil. J Med Virol 78, 281-289. 
Matthijnssens, J., Rahman, M., Martella, V., Xuelei, Y., De Vos, S., De Lenner, K., Ciarlet, M., Buonavoglia, C. \& Van Ranst, M. (2006). Full genomic analysis of human rotavirus strain B4106 and lapine rotavirus strain 30/96 provides evidence for interspecies transmission. J Virol 80, 3801-3810.

O’Mahony, J., Foley, B., Morgan, S., Morgan, J. G. \& Hill, C. (1999). VP4 and VP7 genotyping of rotavirus samples recovered from infected children in Ireland over a 3-year period. J Clin Microbiol 37, 1699-1703.

Pager, C. T., Alexander, J. J. \& Steele, A. D. (2000). South African G4P[6] asymptomatic and symptomatic neonatal rotavirus strains differ in their NSP4, VP8*, and VP7 genes. J Med Virol 62, 208-216.

Parashar, U. D., Gibson, C. J., Bresee, J. S. \& Glass, R. I. (2006). Rotavirus and severe childhood diarrhea. Emerg Infect Dis 12, 304-306.

Pereira, H. G., Azeredo, R. S., Leite, J. P., Barth, O. M., Sutmoller, F., De Farias, V. \& Vidal, M. N. (1983). Comparison of polyacrylamide gel electrophoresis (PAGE), immuno-electron microscopy (IEM) and enzyme immunoassay (EIA) for the rapid diagnosis of rotavirus infection in children. Mem Inst Oswaldo Cruz 78, 483-490.

Rahman, M., Sultana, R., Podder, G., Faruque, A. S., Matthijnssens, J., Zaman, K., Breiman, R. F., Sack, D. A., Van Ranst, M. \& Azim, T. (2005). Typing of human rotaviruses: nucleotide mismatches between the VP7 gene and primer are associated with genotyping failure. Virol J 24, 2-24.

Ramachandran, M., Das, B. K., Vij, A., Kumar, R., Bhambal, S. S., Kesari, N., Rawat, H., Bahl, L., Thakur, S. \& other authors (1996). Unusual diversity of human rotavirus $\mathrm{G}$ and $\mathrm{P}$ genotypes in India. J Clin Microbiol 34, 436-439.

Ramig, R. F. (1997). Genetics of the rotaviruses. Annu Rev Microbiol 51, 225-255.

Rao, C. D., Das, M., Ilango, P., Lalwani, R., Rao, B. S. \& Gowda, K. (1995). Comparative nucleotide and amino acid sequence analysis of the sequence-specific RNA-binding rotavirus nonstructural protein NSP3. Virology 207, 327-333.

Rawdan, S. F., Gabr, M. K., El-Maraghi, S. \& El-Saifi, A. F. (1997). Serotyping of group A rotaviruses in Egyptian neonates and infants less than 1 year old with acute diarrhea. J Clin Microbiol 35, 2996-2998.

Santos, N. \& Hoshino, Y. (2005). Global distribution of rotavirus serotypes/genotypes and its implication for the development and implementation of an effective rotavirus vaccine. Rev Med Virol 15, $29-56$.

Santos, N., Lima, R. C., Nozawa, C. M., Linhares, R. E. \& Gouvea, V. (1999). Detection of porcine rotavirus type G9 and of a mixture of types G1 and G5 associated with Wa-like VP4 specificity: evidence for natural human-porcine genetic reassortment. J Clin Microbiol 37, 2734-2736.

Santos, N., Volotao, E. M., Soares, C. C., Campos, G. S., Sardi, S. I. \& Hoshino, Y. (2005). Predominance of rotavirus genotype G9 during the 1999, 2000, and 2002 seasons among hospitalized children in the city of Salvador, Bahia, Brazil: implications for future vaccine strategies. J Clin Microbiol 43, 4064-4069.

Steele, A. D. \& Ivanoff, B. (2003). Rotavirus strains circulating in Africa during 1996-1999: emergence of G9 strains and P[6] strains. Vaccine 17, 361-367.

Steele, A. D., van Niekerk, M. C. \& Mphalele, M. J. (1995). Geographic distribution of human rotavirus VP4 genotypes and VP7 serotypes in five South African regions. J Clin Microbiol 33, 1516-1519.

Taniguchi, K., Urasawa, T., Morita, Y., Greenberg, H. B. \& Urasawa, S. (1987). Direct serotyping of human rotavirus in stools by an enzymelinked immunosorbent assay using serotype 1-, 2-, 3-, and 4-specific monoclonal antibodies to VP7. J Infect Dis 155, 1159-1166.

Tian, P., Estes, M. K., Hu, Y., Ball, J. M., Zeng, C. Q.-Y. \& Schilling, W. P. (1995). The rotavirus nonstructural glycoprotein NSP4 mobilizes $\mathrm{Ca}^{2+}$ from the endoplasmic reticulum. J Virol 69, 5763-5772.

Timenetsky, M. D. C., Santos, N. \& Gouvea, V. (1994). Survey of rotavirus $\mathrm{G}$ and $\mathrm{P}$ types associated with human gastroenteritis in São Paulo, Brazil, from 1986 to 1992. J Clin Microbiol 32, 2622-2624.

Timenetsky, Mdo, C., Gouvea, V., Santos, N., Carmona, R. C. \& Hoshino, Y. (1997). A novel human rotavirus serotype with dual G5G11 specificity. J Gen Virol 78, 1373-1378.

Varghese, V., Das, S., Singh, N. G. B., Kojima, K., Bhattacharya, S. K., Krishnan, T., Kobayashi, N. \& Naik, T. N. (2004). Molecular characterization of a human rotavirus reveals porcine characteristics in most of the genes including VP6 and NSP4. Arch Virol 149, 155-172.

Volotão, E. M., Soares, C. C., Maranhão, A. G., Rocha, L. N., Hoshino, Y. \& Santos, N. (2006). Rotavirus surveillance in the city of Rio de Janeiro - Brazil during 2000-2004: detection of unusual strains with G8P[4] or G10P[9] specificities. J Med Virol 78, 263-272. 